\title{
The hepatitis B vaccine and autoimmune/ inflammatory syndrome induced by adjuvants: Relationship with Saccharomyces cerevisiae
}

\author{
Carlo Perricone $^{1,2}$, Serena Colafrancesco ${ }^{1,2}$, Yehuda Shoenfeld ${ }^{1,3}$ \\ 1. Zabludowicz Center for Autoimmune Diseases, Sheba Medical Center, Tel-Hashomer, Israel 2. Reumatologia, \\ Dipartimento di Medicina Interna e Specialità Mediche, Sapienza Università di Roma, Rome, Italy. 3. Incumbent of the \\ Laura Schwarz-Kipp Chair for Research of autoimmune diseases, Sackler Faculty of Medicine, Tel-Aviv University, \\ Ramat-Aviv, Israel.
}

Correspondence: Yehuda Shoenfeld. Address: Zabludowicz Center for Autoimmune Diseases Sheba Medical Center, Tel-Hashomer, 52621, Israel. Email: shoenfel@post.tau.ac.il

Received: January 13, 2014

DOI : $10.5430 /$ crim.v1n2p166
Online Published: June 6, 2014

URL: http://dx.doi.org/10.5430/crim.v1n2p166

\section{Abstract}

Several autoimmune disorders have been reported following vaccinations. We describe a patient allergic to yeast vaccinated for HBV who developed the autoimmune/inflammatory syndrome induced by adjuvants (ASIA) with autoantibodies including anti-Saccharomyces Cerevisiae antibodies. Hypersensitivity to yeast may predispose to worse post-vaccination outcome and act synergistically in development of overt disease.

\section{Keywords}

Allergy, Aluminium, Saccharomyces cerevisiae, Yeast, Autoimmune/inflammatory syndrome induced by adjuvants, Autoantibodies, Autoimmunity, Vaccine, Hepatitis B Virus

\section{I ntroduction}

Vaccines represent one of the most significant achievements in the field of preventive medicine, as eradication of infectious diseases becomes possible through vaccination programs ${ }^{[1,2]}$. However, a number of autoimmune disorders have been reported following vaccinations (see Table 1) and the question of a connection between vaccination and autoimmune disorders has raised increasing interests ${ }^{[4-6]}$. With this regard, a heated debate is going on regarding hepatitis $\mathrm{B}(\mathrm{HBV})$ vaccination as a possibly causal agent in triggering autoimmune disorders ${ }^{[7-18]}$.

Nonetheless, post-vaccination phenomena may include, even though rarely, disabling as well as puzzling adverse events ${ }^{[19,20]}$. These phenomena often cannot be easily categorized into a single well-defined autoimmune/inflammatory disease. Hitherto, a new syndrome was introduced and termed 'Autoimmune/inflammatory Syndrome induced by Adjuvants' (ASIA), assembling a spectrum of immune-mediated diseases triggered by an adjuvant stimulus ${ }^{[21]}$. Indeed, notwithstanding that molecular mimicry and bystander/polyclonal activation in a genetically predisposed individual could be involved, there are several components of the vaccine that can trigger an immune response including the adjuvants ${ }^{[22-26]}$. HBV vaccines are grown in Saccharomyces cerevisiae (baker's yeast or brewer's yeast) and contain residual yeast protein ${ }^{[27]}$. The "classical" allergic adverse reactions to these residuals, if any, appear to be rare ${ }^{[28]}$. The use 
of Saccharomyces-based therapeutic vaccines is supported by the evidence of their ability to stimulate tumour or viral-specific CD4 and CD8 T-cell responses ${ }^{[29]}$. However, recent reports suggest that yeast may also trigger autoimmune responses ${ }^{[30]}$.

Herein, we describe the case of a 41 years old man, who reported yeast allergy in his clinical history and developed immediate local reaction to HBV vaccination followed by the overt onset of chronic fatigue syndrome (CFS) and fibromyalgia. The presence of yeast in the vaccine may have created an augmented adjuvant effect, leading to overt disease as well as to the appearance of several autoantibodies including anti-Saccharomyces Cerevisiae antibodies $(\mathrm{ASCA})^{[31]}$.

Table 1. A list of vaccines associated with autoimmune diseases.

\begin{tabular}{ll}
\hline Vaccine & Autoimmune disorder \\
\hline HBV $^{[3,4]}$ & Polyarteritis nodosa, lichen planus, bullous, pemphigoid, Henoch-Schonlein Purpura, \\
& Polyneuropathy, Erythema nodosum, ITP, Myastenia gravis, MS, Uveitis, reactive arthritis, \\
& RA, SLE, CNS demyelination, TM, pemphigus, CFS \\
Anthrax $^{[3]}$ & SLE \\
DTP/Dtap/TT $^{[4]}$ & Optic neuritis, myelitis, GBS, SLE \\
Influenza $^{[4]}$ & SLE, RA, vasculitis, reactive arthritis, GBS \\
MMR $^{[4]}$ & ITP \\
Mumps $^{[4]}$ & T1D \\
Rabies $^{[4]}$ & neuritis GBS \\
HAV $^{[4]}$ & ITP \\
Oral polio $^{[3]}$ & GBS \\
Rubella $^{[3]}$ & Fibromyalgia \\
Swine flu $^{[3]}$ & MS \\
BCG $^{[3,4]}$ & reactive arthritis, polymyositis/dermatomyositis \\
HiB & \\
HPV $^{[3]}$ & T1D \\
\hline
\end{tabular}

Abbreviations: ITP: idiopathic thrombocytopenic purpura; MS: multiple sclerosis; RA: Rheumatoid arthritis; SLE: systemic lupus erythematosus; CNS: central nervous system; TM: transverse myelitis; CFS: chronic fatigue syndrome; GBS: Guillain-Barré Syndrome; T1D: Type 1 diabetes mellitus

\section{Case report}

A 41 years old man was evaluated for CFS and fibromyalgia beginning 15 years earlier following vaccination with HBV-vaccine. Since then, he reported various physical and cognitive symptoms that did not allow him to work or to have social life. He was healthy and functional prior to the vaccination besides a story of allergies including sensitivity to yeast. The patients received in 1997 the amended HBV-vaccine while applying for a new job. Following the third injection, he suffered from a transient local reaction and flu-like symptoms including fatigue, weakness and headaches. Few months later he became chronically ill, with a drastic decline in his overall health characterized by chronic fatigue, un-refreshing sleep, concentration difficulties, a foggy feeling, high and off-balance, and body aches. The physical examination revealed tenderness and swelling of the joints of the ankles, knees and elbows, muscle tenderness, positive tender points, tremors, irregular heartbeat and dyspnoea. The first diagnoses were CSF and fibromyalgia. An electrocardiogram was performed and was suggestive for cardiomyopathy. He underwent echocardiogram and a stress test/SESTA, a MIBI scanning and was diagnosed with a global hypokinesis of the left ventricle, decreased ejection fraction, and an enlargement of the heart. Since then the patient is taking enalapril $20 \mathrm{mg} / \mathrm{die}$. Electromyography/nerve conduction velocities (EMG/NCV) of upper extremities showed bilateral segmental ulnar nerve neuropathies at the elbow level, bilateral brachial plexus level 
neuropathies and mild right median nerve segmental neuropathy at the wrist level. His blood work revealed, elevated protein, albumin and gammaglobulins. During time, a number of autoantibodies tested positive including anti-Saccharomyces cerevisiae (ASCA) [IgA $21.4 \mathrm{EU} / \mathrm{ml}(\mathrm{nv}<20.5 \mathrm{EU} / \mathrm{ml}), \operatorname{IgG} 49.5 \mathrm{EU} / \mathrm{ml}(\mathrm{nv}<22.2 \mathrm{EU} / \mathrm{ml})]$. Decreased levels of complement $\mathrm{C} 3$ and $\mathrm{C} 4$ were shown in more than one occasion. Lymphocytes count revealed decreased total $\mathrm{T}$ cells (CD2, CD3), and decreased helper T cells (CD4).

The patient was advised to rest and avoid all exertion, treatments with anti-depressant helped his depressive symptoms but not the fatigue and other complains. Steroids and hydroxychloroquine were used without success.

\section{Discussion}

An association between vaccines and immune-mediated diseases has been occasionally reported. Moreover, a number of patients can present a plethora of undefined signs and symptoms recently gathered under that condition termed Autoimmune/inflammatory syndrome induced by adjuvants (ASIA) ${ }^{[21]}$. This could be the case of our patient in which unspecific symptoms emerging post-vaccination by the development of an autoimmune response exemplified by the presence of autoantibodies, hypergammaglobulinemia, lymphocytes subpopulations abnormalities and complement consumption. The patient fulfilled the proposed criteria for ASIA diagnosis ${ }^{[21]}$. The largest cohort of cases diagnosed with immune-mediated diseases following immunization HBV vaccine was described by Zafrir et al. ${ }^{[32]}$. The authors depicted 93 patients who, similarly to our report, suffered from a constellation of symptoms including neuropsychiatric, fatigue, muco-cutaneous, musculoskeletal and gastrointestinal complaints with elevated titers of autoantibodies documented in $80 \%$ of sera tested. Eighty six percent of the patients fulfilled the proposed criteria of ASIA ${ }^{[32]}$. HBV vaccine has been associated with a number of autoimmune and non-autoimmune conditions including systemic lupus erythematosus, pemphigus, dermatomyositis, systemic polyarteritis nodosa, chronic fatigue syndrome and fibromyalgia ${ }^{[8,33-45]}$.

The recombinant hepatitis-B vaccine is a highly purified, genetically engineered, single antigen vaccine, which is considered by the medical community as safe. McMahon et al. ${ }^{[46]}$ suggested that the adverse events caused by the plasma-derived HBV vaccine can be due both to the preservative material thimerosal (a mercurial compound that was found to be neurotoxic but that is not included anymore in the HBV vaccines since 1999) and to aluminum (Al) hydroxide, used as an adjuvant ${ }^{[46]}$. Al has been used as an adjuvant for the past 90 years but it is also an experimentally demonstrated neurotoxin. Researches have showed that Al adjuvants have a potential to induce serious immunological disorders in humans. Thus, efforts should be put in clarifying the potential threat of Al containing vaccines ${ }^{[47]}$.

Furthermore, HBV vaccine is grown on Saccharomyces cerevisiae (common bakers' yeast) that carry the surface antigen gene of the virus. As a result of biochemical and biophysical purification, there is no detectable yeast DNA and only trace amounts of yeast proteins $(1 \%-5 \%)$ in the final vaccine products ${ }^{[48]}$. Whether these residual yeast proteins in HBV could act as antigens or allergens in vaccines is unclear ${ }^{[31]}$. In clinical trials, testing for both $\operatorname{IgG}$ and IgE antibodies against yeast proteins were performed in small subsets (50-133 subjects) of volunteers ${ }^{[49-51]}$. A hundred percent of subjects had IgG antibodies against yeast even before vaccination, presumably due to prior exposure to yeast itself. The titers of these $\operatorname{IgG}$ antibodies rose, fell, or remained unchanged after immunization, but showed no consistent pattern and were not related to any clinical complaints after vaccination. Subjects who had anti-yeast antibodies of the IgE class even prior to immunization (1\%-2\%) received the vaccine uneventfully and had no significant rise in the titer of these antibodies ${ }^{[28]}$. Nonetheless, hypersensitivity to yeast is listed in HBV package inserts as a contraindication for HBV administration ${ }^{[52]}$. In a 2006 study, there were 82 reports of HBV post-vaccine adverse events in patients who mentioned a history of allergy to yeast present prior to vaccination. Only 11 recipients described probable or possible anaphylaxis, the other 71 reports described symptoms such as injection site reactions, pain, headache, fever, chills or fatigue. It is thus possible that, besides an overt allergic reaction, hypersensitivity to yeast may predispose to a worse post-vaccination outcome. 
Yeast has numerous involvements in the immune system. Heat-killed Saccharomyces can act like common adjuvants when injected together with preventive vaccines ${ }^{[53]}$. Yeast can reduce the number and function of $\mathrm{T}$ regulatory cells, a mechanism that is involved in the generation of autoimmunity ${ }^{[54]}$. Our case may represent the connection between Saccharomyces cerevisiae (used as an adjuvant in HBV vaccine) and the development of ASIA. Furthermore, in our patient ASCA were detected. ASCA are generally not related to food allergy to yeast ${ }^{[28,55]}$. These autoantibodies are quite specific for Crohn's disease, but a growing number of studies have detected high levels of ASCAs in patients affected with autoimmune diseases as compared with healthy controls, including SLE, antiphospholipid syndrome, diabetes mellitus type 1 and rheumatoid arthritis ${ }^{[29,30,56]}$.

\section{Final remarks}

Our case, besides showing another face of ASIA, has several other points of interest. First, we depicted a previously healthy subject who developed, following HBV vaccination, a protean clinical picture, yet not fully defined, accompanied by a diverse production of autoantibodies. The presence of yeast residuals in the vaccine may have amplified the immune response in a subject who was allergic to the yeast, leading to the development of ASCA and of overt disease, suggesting that a causal relationship between HBV vaccination and ASIA cannot be excluded. For these reasons, even though the risk: benefit ratio is still overwhelmingly in favor of HBV vaccinations, we now face the challenge of developing risk-free vaccines ${ }^{[57]}$. Nonetheless, the allergy screen for yeast before vaccination is mandatory, and further studies are needed to address whether these subjects can be vaccinated and eventually are more prone to develop ASIA.

\section{Disclosure}

An informed consent has been received from the patient to present his case. Yehuda Shoenfeld has served as an expert witness in cases (including the one reported in this article) involving adverse vaccine reaction in the no-fault U.S. National Vaccine Injury Compensation Program.

\section{References}

[1] Aron-Maor A, Shoenfeld Y Vaccination and systemic lupus erythematosus: the bidirectional dilemmas. Lupus. 2001 ; $10: 237-40$. http://dx.doi.org/10.1191/096120301673085478

[2] Kivity S, Agmon-Levin N, Blank M, Shoenfeld Y. Infections and autoimmunity--friends or foes? Trends Immunol. 2009; 30: 409-14. http://dx.doi.org/10.1016/j.it.2009.05.005

[3] Tishler M, Shoenfeld Y. Vaccination may be associated with autoimmune diseases. Isr Med Assoc J. 2004; 6: 430-2.

[4] Cohen AD, Shoenfeld Y. Vaccine-induced Autoimmunity. J Autoimmunity. 1996; 9: 699-703. http://dx.doi.org/10.1006/jaut.1996.0091

[5] Shoenfeld Y, Aron-Maor A. Vaccination and autoimmunity - 'Vaccinosis': a dangerous liaison? J Autoimmunity. 2000; 14 : 1-10. http://dx.doi.org/10.1006/jaut.1999.0346

[6] Perricone C, Agmon-Levin N, Valesini G, Shoenfeld Y. Vaccination in patients with chronic or autoimmune rheumatic diseases: the ego, the id and the superego. Joint Bone Spine. 2012; 79: 1-3. http://dx.doi.org/10.1016/j.jbspin.2011.10.006

[7] Marshall E. A shadow falls on hepatitis B vaccination effort. Science. 1998; 281: 630-631. http://dx.doi.org/10.1126/science.281.5377.630

[8] Altman A, Szyper-Kravitz M, Shoenfeld Y. HBV vaccine and dermatomyositis: is there an association? Rheumatol Int. 2008; 28: 609-12. http://dx.doi.org/10.1007/s00296-007-0485-4

[9] $\mathrm{Wu}$ YL, Tsai MH, Liu LL. Erythema nodosum and hepatitis B: a case report and literature review. J Microbiol Immunol Infect. 2008; 41: 437-9.

[10] Rebora A, Rongioletti F, Drago F, Parodi. Lichen planus as a side effect of HBV vaccination. Dermatology. $1999 ; 198: 1-2$. http://dx.doi.org/10.1159/000018054

[11] Saadoun D, Cacoub P, Mahoux D, Sbai A, Piette JC. Postvaccine vasculitis: A report of three cases. Rev Med Interne. 2001; 22: 172-6. http://dx.doi.org/10.1016/S0248-8663(00)00307-6

[12] Geier MR, Geier DA. A case-series of adverse events, positive re-challenge of symptoms, and events in identical twins following hepatitis B vaccination: analysis of the Vaccine Adverse Event Reporting System (VAERS) database and literature review. Clin Exp Rheumatol. 2004; 22: 749-55

Published by Sciedu Press 
[13] Basra G, Jajoria P, Gonzalez E. Rheumatoid arthritis and Swine influenza vaccine: A case report. Case Rep Rheumatol. 2012; 785028.

[14] Schattner A. Consequence or coincidence? The occurrence, pathogenesis and significance of autoimmune manifestations after viral vaccines. Vaccine. 2005; 23: 3876-86. http://dx.doi.org/10.1016/j.vaccine.2005.03.005

[15] Renard JL, Guillamo JS, Ramirez JM, Taillia H, Felten D, Buisson Y. Acute transverse cervical myelitis following hepatitis B vaccination. Evolution of anti-HBs antibodies. Presse Med. 1999; 28: 1290-2.

[16] Khamaisi M, Shoenfeld Y, Orbach H. Guillain-Barré syndrome following hepatitis B vaccination. Clin Exp Rheumatol. 2004; 22: 767-70.

[17] Kuruma KA, Borba EF, Lopes MH, de Carvalho JF, Bonfá E. Safety and efficacy of hepatitis B vaccine in systemic lupus erythematosus. Lupus. 2007; 16: 350-4. http://dx.doi.org/10.1177/0961203307078225

[18] Appel S, Chapman J, Shoenfeld Y. Infection and vaccination in chronic fatigue syndrome: myth or reality? Autoimmunity. 2007; 40: 48-53. http://dx.doi.org/10.1080/08916930701197273

[19] Perricone C, Alessandri C, Valesini G. 'ASIA' - Autoimmune/inflammatory syndrome induced by adjuvants: even and odd. Reumatismo. 2011; 63: 63-6. http://dx.doi.org/10.4081/reumatismo.2011.63

[20] Agmon-Levin N, Paz Z, Israeli E, Shoenfeld Y. Vaccines and autoimmunity. Nat Rev Rheumatol. 2009; 5: 648-52. http://dx.doi.org/10.1038/nrrheum.2009.196

[21] Shoenfeld Y, Agmon-Levin N. 'ASIA' - autoimmune/inflammatory syndrome induced by adjuvants. J Autoimmun. 2011 ; 36: 4-8. http://dx.doi.org/10.1016/j.jaut.2010.07.003

[22] Israeli E, Agmon-Levin N, Blank M, Shoenfeld Y. Adjuvants and autoimmunity. Lupus. 2009; 18: 1217-25. http://dx.doi.org/10.1177/0961203309345724

[23] Timmermans K, Plantinga TS, Kox M, Vaneker M, Scheffer GJ, et al. Blueprints of Signaling Interactions between Pattern Recognition Receptors: Implications for the Design of Vaccine Adjuvants. Clin Vaccine Immunol. 2013; 20: 427-32. http://dx.doi.org/10.1128/CVI.00703-12

[24] Shklovskaya E, O'Sullivan BJ, Ng LG, Roediger B, Thomas R, Weninger W, Fazekas de St Groth B. Langerhans cells are precommitted to immune tolerance induction. Proc Natl Acad Sci U S A. 2011; 108: 18049-54.

http://dx.doi.org/10.1073/pnas.1110076108

[25] Chuai X, Chen H, Wang W, Deng Y, Wen B, Ruan L, Tan W. Poly(I:C)/alum mixed adjuvant priming enhances HBV subunit vaccine-induced immunity in mice when combined with recombinant adenoviral-based HBV vaccine boosting. PLoS One. 2013; 8: e54126. http://dx.doi.org/10.1371/journal.pone.0054126

[26] Alijotas-Reig J, Garcia-Gimenez V, Llurba E, Vilardell-Tarrés M. Autoimmune/inflammatory syndrome (ASIA) induced by biomaterials injection other than silicone medical grade. Lupus. 2012; 21: 1326-34. http://dx.doi.org/10.1177/0961203312458838

[27] Grabenstein JD. ImmunoFacts: Vaccines and Immunologic Drugs - 2012 (37th revision). St Louis, MO: Wolters Kluwer Health, 2011

[28] DiMiceli L, Pool V, Kelso JM, Shadomy SV, Iskander J, Team VAERS. Vaccination of yeast sensitive individuals: review of safety data in the US vaccine adverse event reporting system (VAERS). Vaccine. 2006; 24: 703-707. http://dx.doi.org/10.1016/j.vaccine.2005.07.069

[29] Tamburini BA, Kedl RM, Bellgrau D. IL-6-inducing whole yeast-based immunotherapy directly controls IL-12-dependent CD8 T-cell responses J Immunother. 2012; 35: 14-22. http://dx.doi.org/10.1097/CJI.0b013e3182356888

[30] Rinaldi M, Perricone R, Blank M, Perricone C, Shoenfeld Y. Anti-Saccharomyces cerevisiae Autoantibodies in Autoimmune Diseases: from Bread Baking to Autoimmunity. Clin Rev Allergy Immunol. 2013 Jan 5. http://dx.doi.org/10.1007/s12016-012-8344-9

[31] Bartůnková J, Kayserová J, Shoenfeld Y. Allergy and autoimmunity: parallels and dissimilarity: the yin and yang of immunopathology. Autoimmun Rev. 2009; 8: 302-8. http://dx.doi.org/10.1016/j.autrev.2008.09.004

[32] Zafrir Y, Agmon-Levin N, Paz Z, Shilton T, Shoenfeld Y. Autoimmunity following hepatitis B vaccine as part of the spectrum of 'Autoimmune (Auto-inflammatory) Syndrome induced by Adjuvants' (ASIA): analysis of 93 cases. Lupus. 2012; 21 : 146-52. http://dx.doi.org/10.1177/0961203311429318

[33] Agmon-Levin N, Zafrir Y, Paz Z, Shilton T, Zandman-Goddard G, Shoenfeld Y. Ten cases of systemic lupus erythematosus related to hepatitis B vaccine. Lupus. 2009; 18: 1192-7. http://dx.doi.org/10.1177/0961203309345732

[34] Battafarano DF, Battafarano NJ, Larsen L, Dyer PD, Older SA, Muehlbauer S, et al. Antigen-specific antibody responses in lupus patients following immunization. Arthritis Rheum 1998; 41: 1828-34.

http://dx.doi.org/10.1002/1529-0131(199810)41:10<1828::AID-ART15>3.0.CO;2-T 
[35] Senécal J-L, Bertrand C, Coutlée F. Severe exacerbation of systemic lupus erythematosus after hepatitis B vaccination and importance of pneumococcal vaccination in patients with autosplenectomy: comment on the article by Battafarano et al [letter]. Arthritis Rheum 1999; 42: 1307-8. http://dx.doi.org/10.1002/1529-0131(199906)42:6<1307::AID-ANR38>3.0.CO;2-L

[36] Maillefert JF, Tavernier C, Sibilia J, Vignon E. Exacerbation of systemic lupus erythematosus after hepatitis B vaccination: comment on the article by Battafarano et al and the letter by Senécal et al. Arthritis Rheum. 2000; 43: 468-9. http://dx.doi.org/10.1002/1529-0131(200002)43:2<468::AID-ANR32>3.0.CO;2-K

[37] Berkun Y, Mimouni D, Shoenfeld Y. Pemphigus following hepatitis B vaccination--coincidence or causality? Autoimmunity. 2005; 38: 117-9. http://dx.doi.org/10.1080/08916930400027078

[38] de Carvalho JF, Pereira RM, Shoenfeld Y. Systemic polyarteritis nodosa following hepatitis B vaccination. Eur J Intern Med. 2008; 19: 575-8. http://dx.doi.org/10.1016/j.ejim.2007.06.035

[39] Exley C, Swarbrick L, Gherardi RK, Authier FJ. A role for the body burden of aluminium in vaccine-associated macrophagic myofasciitis and chronic fatigue syndrome. Med Hypotheses. 2009; 72: 135-9. http://dx.doi.org/10.1016/j.mehy.2008.09.040

[40] Nancy AL, Shoenfeld Y. Chronic fatigue syndrome with autoantibodies--the result of an augmented adjuvant effect of hepatitis-B vaccine and silicone implant. Autoimmun Rev. 2008; 8: 52-5. http://dx.doi.org/10.1016/j.autrev.2008.07.026

[41] Ablin JN, Shoenfeld Y, Buskila D. Fibromyalgia, infection and vaccination: two more parts in the etiological puzzle. J Autoimmun. 2006; 27: 145-52. http://dx.doi.org/10.1016/j.jaut.2006.09.004

[42] Mikaeloff Y, Caridade G, Suissa S, Tardieu M. Hepatitis B vaccine and the risk of CNS inflammatory demyelination in childhood. Neurology. 2009; 72: 873-80. http://dx.doi.org/10.1212/01.wnl.0000335762.42177.07

[43] Hernán MA, Jick SS, Olek MJ, Jick H. Recombinant hepatitis B vaccine and the risk of multiple sclerosis A prospective study. Neurology. 2004; 63: 838-842. http://dx.doi.org/10.1212/01.WNL.0000138433.61870.82

[44] Konstantinou D, Paschalis C, Maraziotis T, Dimopoulos P, Bassaris H, Skoutelis A. Two episodes of leukoencephalitis associated with recombinant Hepatitis B vaccination in a single patient. Clinical Infectious Diseases. 2001; 33: 1772-3. http://dx.doi.org/10.1086/322617

[45] de Carvalho JF, Shoenfeld Y. Status epilepticus and lymphocytic pneumonitis following hepatitis B vaccination. Eur J Intern Med. 2008; 19: 383-5. http://dx.doi.org/10.1016/j.ejim.2007.10.005

[46] McMahon MI, Ackland GJ. Aluminium: Simple metal no more. Nat Mater. 2010; 9: 607-8. http://dx.doi.org/10.1038/nmat2817

[47] Tomljenovic L, Shaw CA. Aluminum Vaccine Adjuvants: Are they Safe? Current Medicinal Chemistry. 2011; 18: $2630-2637$. http://dx.doi.org/10.2174/092986711795933740

[48] ENGERIX-B (GlaxoSmithKline) Hepatitis B vaccine (recombinant). GlaxoSmithKline; 2004. Vaccine package insert.

[49] Petre J, Van Wijnendaele F, De Neys B, Conrath K, Van Opstal O, Hanser P, et al. Development of a hepatitis B vaccine from transformed yeast cells. Postgrad Med J. 1987; 63: 73-81.

[50] Wiedermann G, Scheiner O, Ambrosch F, Kraft D, Kollaritsch H, Kremsner P, Hauser P, Simoen E, André FE, Safary A. Lack of induction of IgE and IgG antibodies to yeast in humans immunized with recombinant hepatitis B vaccines. Int Arch Allergy Appl Immunol. 1988; 85: 130-2. http://dx.doi.org/10.1159/000234489

[51] West DJ. Clinical experience with hepatitis B vaccines. Am J Infect Control. 1989; 17: 172-80. http://dx.doi.org/10.1016/0196-6553(89)90213-7

[52] Kelso JM, Li JT, Nicklas RA, Blessing-Moore J, Cox L, Lang DM, et al; Joint Task Force on Practice Parameters; Joint Task Forcce on Practice Parameters for Allergy \& Immunology. Adverse reactions to vaccines. Ann Allergy Asthma Immunol. 2009; 103: S1-14. http://dx.doi.org/10.1016/S1081-1206(10)60350-X

[53] Berner VK, Sura ME, Hunter KW Jr. Conjugation of protein antigen to microparticulate beta-glucan from Saccharomyces cerevisiae: a new adjuvant for intradermal and oral immunizations. Appl Microbiol Biotechnol. 2008; 80: $1053-61$. http://dx.doi.org/10.1007/s00253-008-1618-8

[54] Cereda V, Vergati M, Huen NY, di Bari MG, Jochems C, Intrivici C, et al. Maturation of human dendritic cells with Saccharomyces cerevisiae (yeast) reduces the number and function of regulatory $\mathrm{T}$ cells and enhances the ratio of antigen-specific effectors to regulatory T cells. Vaccine. 2011; 29: 4992-9. http://dx.doi.org/10.1016/j.vaccine.2011.04.101

[55] Bartunková J, Kolárová I, Sedivá A, Hölzelová E. Antineutrophil cytoplasmic antibodies, anti-Saccharomyces cerevisiae antibodies, and specific IgE to food allergens in children with inflammatory bowel diseases. Clin Immunol. 2002; 102: 162-8. http://dx.doi.org/10.1006/clim.2001.5145

[56] Cinemre H, Bilir C, Gokosmanoglu F, Kadakal F. Anti-Saccharomyces cerevisiae antibodies in acute myocardial infarction. J Investig Med. 2007; 55: 444-9. http://dx.doi.org/10.2310/6650.2007.00024

[57] Borchers AT, Keen CL, Shoenfeld Y, Silva J Jr, Gershwin ME. Vaccines, viruses, and voodoo. J Investig Allergol Clin Immunol. 2002; 12: 155-68. 